\title{
A TECNOLOGIA NAS LICENCIATURAS EM LETRAS PORTUGUÊS/INGLÊS DAS UNIVERSIDADES PÚBLICAS PARANAENSES: UMA ANÁLISE DOCUMENTAL
}

\author{
Thais Mazotti Lins ${ }^{1}$ \\ Clodis Boscarioli ${ }^{2}$
}

\begin{abstract}
RESUMO: A tecnologia pode contribuir para o ensino como uma profícua parceira na área da educação, inclusive tendo sua implementação aconselhada nos documentos que orientam as políticas públicas, devendo, portanto, ser um alvo da formação de professores para que possam incluí-la em sua rotina de trabalho. O tema central desse artigo é a investigação de como a tecnologia vem sendo abordada nos cursos de Licenciatura em Letras Português/Inglês das universidades públicas paranaenses. Uma análise de seus documentos reguladores foi realizada, objetivando averiguar se, e como, essas universidades abordam a tecnologia na concepção de seus cursos. Foi constatado que metade delas não o faz, e que a outra metade faz isso ou pela inclusão em disciplinas ofertadas ou contemplando-a como objetivo a ser atingido no curso. Nota-se, portanto, a necessidade de uma revisão nesses documentos norteadores para capacitar seus egressos ao uso pedagógico da tecnologia, de forma apropriada. Próximas pesquisas poderão analisar o reflexo que o impacto dessa formação em tecnologias, ou sua falta, causa em sala de aula, na atuação dos professores e no alunado.
\end{abstract}

Palavras-chave: Ensino com Tecnologias; Ensino Superior; Formação Inicial.

\section{THE TECHNOLOGY IN PORTUGUESE/ENGLISH LICENSEES IN PARANAIAN PUBLIC UNIVERSITIES: A DOCUMENTARY ANALYSIS}

\begin{abstract}
Technology can contribute to teaching as a profitable partner in the field of education, including having its implementation advised in the documents that guide public policies, and should therefore be a target of teacher training so that they can include it in their work routine. The central theme of this article is the investigation of how the technology has been approached in the courses of Licenciatura in Portuguese/English Literature of the public universities of Paraná. An analysis of their regulatory documents was carried out, aiming to find out if, and how, these universities approach the technology in the conception of their courses. It was verified that half of

\footnotetext{
${ }^{1}$ Graduada em Letras Português/Inglês pela Universidade Estadual do Oeste do Paraná, Especialista em Informática Instrumental Aplicada a Educação pela Universidade Tecnológica Federal do Paraná e em Língua Inglesa pela Universidade Estadual do Oeste do Paraná, com Mestrado em andamento na área de ensino pela mesma universidade. Contato: thaismazotti@gmail.com

2 Professor na Universidade Estadual do Oeste do Paraná. Graduado em Informática e especialista em Ciência da Computação pela Universidade Estadual de Ponta Grossa. Mestre em Informática pela Universidade Federal do Paraná e Doutor em Engenharia elétrica pela Universidade de São Paulo. Também especialista em Formulação e Gestão de Políticas Públicas pela Escola de Governo do Paraná em parceria com a Universidade Estadual do Oeste do Paraná. Contato: boscarioli@gmail.com
}

Programas de Pós-Graduação em Ciências Sociais e Filosofia - UNIOESTE - Rua da Faculdade 645. Toledo - PR. CEP 85.903-000 Email: revistaalamedas@gmail.com 
them do not, and that the other half does this either by inclusion in offered courses or contemplating it as an objective to be reached in the course. Therefore, it is necessary to review these guiding documents in order to enable their graduates to use the pedagogical technology appropriately. Future research may analyze the reflection that the impact of this training in technologies, or its lack, causes in the classroom, in the work of the teachers and in the student.

Keywords: Teaching with Technologies; Higher education; Initial formation.

\section{INTRODUÇÃO}

A palavra tecnologia tem princípio no grego "tekhne" que significa "técnica, arte, ofício", e deriva de uma das variáveis de um verbo que significa fabricar, produzir, construir. Além de "tekhne", tecnologia conta ainda com o sufixo "logia", do grego logus, que significa "razão, estudo" (VERASZTO et al., 2008). Não é um termo recente, e tem uso amplo, que compreende, por exemplo, de artefatos como arco e flecha, à calculadora mecânica e a máquina a vapor, que provocaram profundas transformações no processo produtivo, às Tecnologias Digitais de Informação e Comunicação (TDIC).

Segundo as Diretrizes Curriculares, os professores devem ofertar atividades de estudo que contem com a utilização de novas tecnologias de comunicação (BRASIL, 2010, p. 52). As Diretrizes abordam no termo "tecnologia" tanto o giz e os livros quanto o acesso dos estudantes à biblioteca, ao rádio, à televisão e à internet aberta, destacando que a infra-estrutura tecnológica deve garantir isso aos estudantes, e que "essa distância necessita ser superada, mediante aproximação dos recursos tecnológicos de informação e comunicação, estimulando a criação de novos métodos didático-pedagógicos" (BRASIL, 2010, p. 22 e 28).

A Base Nacional Comum Curricular (BNCC), documento normativo na prática da gestão escolar e pedagógica para as redes de ensino públicas e privadas, menciona que "estamos em um momento histórico muito diferente de 50, 40, 30, 20, 10 anos atrás" (BRASIL, 2018, p. 13). Perante essas transformações, "a referência que temos de escola já não atende ao mundo atual. As necessidades de formação hoje são outras. E a vida continua mudando em um ritmo cada vez mais veloz, em função, dentre outras coisas, do avanço do desenvolvimento da tecnologia e de sua presença em nossa vida" (BRASIL, 2018, p. 13). 
As crianças dessa geração do deslanchar da tecnologia ficaram conhecidas como fazendo parte da geração do milênio, os millennials (GIBSON; SODEMAN, 2014, p. 66), que aprendem, tem acesso e interagem com tecnologias de forma diferente. Levando isso em conta o professor deve estar preparado para prover uma educação que valorize as habilidades, características e realidade dessa geração de alunos - uma geração conhecida "por sua capacidade de multitarefa e por utilizar muitos dispositivos tecnológicos simultaneamente. Essa é uma grande diferença das gerações anteriores" (GIBSON; SODEMAN, 2014, p. 66).

Perante essa expectativa dos millennials qual seria a incumbência do professor? A BNCC indica que uma das coisas que obriga o professor a rever a maneira como ensina é a tecnologia (BRASIL, 2018). Ainda, aponta que a segunda de suas dez competências gerais é "exercitar a curiosidade intelectual" por, dentre outras coisas, “criar soluções (inclusive tecnológicas) com base nos conhecimentos das diferentes áreas" (BRASIL, 2018, p. 24). Além disso, sua quinta competência é:

compreender, utilizar e criar tecnologias digitais de informação e comunicação de forma crítica, significativa, reflexiva e ética nas diversas práticas sociais (incluindo as escolares) para se comunicar, acessar e disseminar informações, produzir conhecimentos, resolver problemas e exercer protagonismo e autoria na vida pessoal e coletiva (BRASIL, 2018, p. 24).

Este documento reconhece, portanto, a importância, e atribui ao professor à tarefa de utilizar a tecnologia no cotidiano, seja qual for sua área de formação e de atuação. Em complemento, as Diretrizes Curriculares Nacionais (BRASIL, 2010) - que estabelecem normas obrigatórias à Educação Básica - aconselham que as tecnologias devem "ser usadas e adaptadas para servir a fins educacionais e como tecnologia assistiva", tendo seus "recursos e métodos (...) inseridos no cotidiano escolar" (BRASIL, 2010, p. 28), pois "constituem-se, cada vez mais, condição para que a pessoa saiba se posicionar frente a processos e inovações que a afetam” (BRASIL, 2010, p. 28).

Os professores têm buscado, ainda que com dificuldade e pouca infraestrutura, inserir as tecnologias em suas práticas, mas, muitas vezes, o resultado é que esse uso não surte o efeito esperado de um ensino mais integrador, que auxilie no aprendizado, que complemente o papel do professor, agregando outros conhecimentos às aulas. Em 
outros casos, esse uso ocorre sem planejamento pedagógico efetivo, e mais como marketing institucional, numa tentativa de se mostrar atual, inovador e moderno, o que vai ao encontro do mencionado nas Diretrizes: "os docentes creem que acompanham a era digital apenas porque digitam e imprimem textos, têm e-mail" (BRASIL, 2010, p. 27) e fazem uso de tecnologias digitais.

Constata-se, dessa forma, que ainda que exista um discurso de incentivo voltado ao trabalho com tecnologias para o ensino, inclusive aportado em documentos que regem o trabalho do professor, há certo descompasso entre aquilo que se orienta e o que, de fato, tem sido realizado em sala de aula, que muitas vezes se traduz na seguinte realidade: os professores possuem um anseio em utilizar tecnologia, mas esse desejo vem acompanhado de uma incerteza e um desamparo em como proceder.

Esse desalinho da dificuldade de adoção enfrentada pelos professores já foi apontado por alguns autores como ocasionado pela formação inicial recebida. Por não terem tido a instrução e o incentivo necessários para fazer uso da tecnologia quando inseridos no mercado de trabalho, ou o terem recebido de forma incipiente, encontramse agora, que estão em sala de aula, despreparados para isso. Como afirma Mello (2018, p. 66): "para que se construam novas práticas, necessita-se, entre outros fatores, de conhecimento que ofereça subsídios teóricos e metodológicos para que as TDIC sejam utilizadas de forma efetiva e significativa".

Em consonância a isso, Gonçalves e Nunes (2006, p. 5) já apontaram para "a superficialidade dos cursos perante os desafios da contemporaneidade, desarticulados do contexto histórico-social", o que, segundo os autores, "impossibilita aos formandos imprimir intencionalidade à prática" (GONÇALVES; NUNES, 2006, p. 6).

O cenário supracitado revela a importância que a graduação exerce na vida profissional, sendo fonte de conhecimento de grande impacto na posterior atividade de trabalho dos alunos-professores. Cônscios do papel que a formação inicial docente possui e a influência das tecnologias no cotidiano, e dado o foco de interesse dessa investigação, questionamos: "O que se mostra sobre as tecnologias no curso de licenciatura em Letras Português/Inglês das universidades públicas do estado do Paraná?", buscando compreender de que modo as tecnologias são consideradas no âmbito da formação inicial dos futuros professores de língua portuguesa e inglesa, isto 
é, como esse curso trabalha com a tecnologia, e como isso é demonstrado em seus documentos oficiais.

O documento segue assim organizado: A Seção 2 traz uma descrição dos procedimentos adotados na realização desse estudo, seguida da análise documental realizada apresentada na Seção 3. Por fim, na Seção 4 tem-se a conclusão e perspectivas da pesquisa.

\section{DELINEAMENTO DA PESQUISA}

Considerando nossa discussão introdutória, os documentos dos quatorze cursos de Letras Português/Inglês das universidades públicas paranaenses foram analisados à luz de como a tecnologia está sendo abordada nessa formação inicial, vendo a aderência desses cursos aos benefícios da inclusão das tecnologias na educação. $O$ foco na habilitação Português/Inglês tem por razão as muitas vertentes existentes para os cursos de licenciatura em Letras, como Letras Português, Português/Espanhol, Português/Francês, Inglês, Língua Estrangeira Moderna (que, embora vise formar professores de língua portuguesa e inglesa, possui o foco também em outros idiomas), Português/Italiano, Português/Alemão, Português/Libras, Português/Grego, e diversas outras, que fogem ao escopo desta pesquisa e que, por esse motivo, não foram abrangidas, apesar de serem também ofertadas no estado do Paraná. Embora a pesquisa tenha sido centralizada nas universidades públicas do Paraná, a metodologia adotada pode ser aplicada a outros estados e contextos.

Ainda que existam pesquisas como as de Mateus (2004) que focaliza os professores em pré-serviço, buscando discutir como se deu, durante um curso de graduação em Letras, o uso do computador, e descrever as visões desses alunos/professores do último ano do curso sobre a utilização desse recurso em sua prática pedagógica, e de Baptista (2014) que objetiva investigar as reflexões de professores de inglês em formação inicial sobre o uso de novas tecnologias para o ensino e aprendizagem de línguas com base em produções textuais escritas realizadas pelos alunos de Letras, há uma escassez de pesquisas que tomem como fenômeno de estudo as tecnologias (vista de forma geral, não centralizada apenas no computador) sendo abordada na Licenciatura em Letras Português/Inglês. Esta condição favorece e 
justifica a realização da pesquisa ora relatada visando identificar como as quatorze universidades paranaenses têm preparado os professores para a prática em sala de aula.

Em busca desses esclarecimentos sob a temática da tecnologia nesses cursos realizou-se, num primeiro momento, uma pesquisa no Portal da Capes e no Google Acadêmico averiguando a existência de pesquisas com este tema e, constatada a ausência de trabalhos, passou-se para uma segunda averiguação. Foi realizada uma coleta de dados, durante o mês de dezembro de 2018, por meio de uma busca no sítio do Ministério da Educação (MEC) pelos cursos ofertados por instituições de ensino superior públicas no estado do Paraná. Desse levantamento, emergiram um total de 14 instituições que oferecem a licenciatura em Letras Português/Inglês (Quadro 1). Após esse levantamento dos cursos, buscou-se ter acesso aos documentos que os regem, a partir do site oficial de cada uma dessas universidades, buscando suas Ementas, Matrizes Curriculares e Projetos Pedagógicos.

Quadro 1: Documentos das universidades públicas paranaenses com curso de Letras Português/Inglês

\begin{tabular}{|c|c|c|}
\hline INSTITUIÇÃO & $\begin{array}{l}\text { CAMPU } \\
\text { S }\end{array}$ & DOCUMENTO \\
\hline $\begin{array}{l}\text { Universidade Estadual do Oeste do } \\
\text { Paraná (UNIOESTE) }\end{array}$ & Cascavel & Projeto Pedagógico \\
\hline $\begin{array}{l}\text { Universidade Estadual do Oeste do } \\
\text { Paraná (UNIOESTE) }\end{array}$ & $\begin{array}{l}\text { Foz do } \\
\text { Iguaçu }\end{array}$ & Projeto Pedagógico \\
\hline $\begin{array}{l}\text { Universidade Estadual do Oeste do } \\
\text { Paraná (UNIOESTE) }\end{array}$ & $\begin{array}{r}\text { Marechal } \\
\text { Cândido Rondon }\end{array}$ & Projeto Pedagógico \\
\hline $\begin{array}{c}\text { Universidade Estadual de Ponta Grossa } \\
\text { (UEPG) }\end{array}$ & $\begin{array}{l}\text { Ponta } \\
\text { Grossa }\end{array}$ & Projeto Pedagógico \\
\hline $\begin{array}{l}\text { Universidade Estadual de Maringá } \\
\text { (UEM) }\end{array}$ & Maringá & $\begin{array}{l}\text { Projeto Pedagógico } \\
\text { e Matriz Curricular }\end{array}$ \\
\hline $\begin{array}{l}\text { Universidade Estadual de Maringá } \\
\text { (UEM) }\end{array}$ & distância & Projeto Pedagógico \\
\hline $\begin{array}{l}\text { Universidade Estadual do Centro-Oeste } \\
\text { (UNICENTRO) }\end{array}$ & $\begin{array}{l}\text { Guarapua } \\
\text { va }\end{array}$ & Matriz Curricular \\
\hline $\begin{array}{l}\text { Universidade Estadual do Paraná } \\
\text { (UNESPAR) }\end{array}$ & $\begin{array}{l}\text { Campo } \\
\text { Mourão }\end{array}$ & Matriz Curricular \\
\hline $\begin{array}{l}\text { Universidade Estadual do Paraná } \\
\text { (UNESPAR) }\end{array}$ & Paranavaí & Matriz Curricular \\
\hline
\end{tabular}




\begin{tabular}{|c|c|c|}
\hline $\begin{array}{c}\text { Universidade Estadual do Paraná } \\
\text { (UNESPAR) }\end{array}$ & $\begin{array}{c}\text { União da } \\
\text { Vitória }\end{array}$ & Matriz Curricular \\
\hline $\begin{array}{c}\text { Universidade Estadual do Paraná } \\
\text { (UNESPAR) }\end{array}$ & $\begin{array}{c}\text { Paranagu } \\
\text { á }\end{array}$ & Matriz Curricular \\
\hline $\begin{array}{c}\text { Universidade Estadual do Norte Paraná } \\
\text { (UENP) }\end{array}$ & $\begin{array}{c}\text { Cornélio } \\
\text { Procópio }\end{array}$ & $\begin{array}{c}\text { Projeto Pedagógico } \\
\text { e Matriz Curricular }\end{array}$ \\
\hline $\begin{array}{c}\text { Instituto Federal do Paraná (IFPR) } \\
\text { Paraná (UTFPR) }\end{array}$ & Palmas & $\begin{array}{c}\text { Projeto } \\
\text { Pedagógico, Ementa e } \\
\text { Matriz Curricular }\end{array}$ \\
\hline $\begin{array}{c}\text { Universidade Tecnológica Federal do } \\
\text { Paroto Pedagógico }\end{array}$ & $\begin{array}{c}\text { Projeto Pato } \\
\text { e Matriz Curricular }\end{array}$ \\
\hline
\end{tabular}

Fonte: Os autores (2019)

A motivação para analisar esses documentos ocorreu tendo em vista que estes podem explicitar, mesmo que em menor grau, o que tem sido exposto - e com qual objetivo, aos graduandos nas aulas. Dentre esses cursos ofertados em diversos campi há um curso na modalidade a distância ofertado pela UEM, sendo a única licenciatura EaD em Letras Português/Inglês do Paraná analisada. A próxima seção, por seu turno, abarca como a tecnologia vem sendo tratada nos documentos oficiais dos cursos de Letras Português/Inglês das universidades públicas paranaenses.

\section{DESCRIÇÃO E ANÁLISE DOS DOCUMENTOS}

Com base na análise dos dezenove documentos a que se teve acesso pode-se notar que metade das universidades não faz menção a tecnologia, o que pode ser visto no Quadro 2.

Quadro 2: Menção a tecnologia nos documentos dos cursos de Letras Português/Inglês analisados

\begin{tabular}{|c|c|c|c|}
\hline INSTITUIÇÃ̃O & CAMPU & DOCUMEN & $\begin{array}{c}\text { MENÇ } \\
\text { TOS A } \\
\text { TECNOLOGIA }\end{array}$ \\
\hline $\begin{array}{c}\text { Universidade Estadual do } \\
\text { Oeste do Paraná (UNIOESTE) }\end{array}$ & Cascavel & $\begin{array}{c}\text { Projeto } \\
\text { Pedagógico }\end{array}$ & Não \\
\hline $\begin{array}{c}\text { Universidade Estadual do } \\
\text { Oeste do Paraná (UNIOESTE) }\end{array}$ & $\begin{array}{c}\text { Foz do } \\
\text { Iguaçu }\end{array}$ & $\begin{array}{c}\text { Projeto } \\
\text { Pedagógico }\end{array}$ & Sim \\
\hline Universidade Estadual do & Marechal & Projeto & \\
\hline
\end{tabular}




\begin{tabular}{|c|c|c|c|}
\hline Oeste do Paraná (UNIOESTE) & Cândido Rondon & Pedagógico & \\
\hline $\begin{array}{l}\text { Universidade Estadual de } \\
\text { Ponta Grossa (UEPG) }\end{array}$ & $\begin{array}{l}\text { Ponta } \\
\text { Grossa }\end{array}$ & $\begin{array}{l}\text { Projeto } \\
\text { Pedagógico }\end{array}$ & Sim \\
\hline $\begin{array}{l}\text { Universidade Estadual de } \\
\text { Maringá (UEM) }\end{array}$ & Maringá & $\begin{array}{c}\text { Projeto } \\
\text { Pedagógico e Matriz } \\
\text { Curricular }\end{array}$ & Sim \\
\hline $\begin{array}{l}\text { Universidade Estadual de } \\
\text { Maringá (UEM) }\end{array}$ & $\begin{array}{r}\text { À } \\
\text { distância }\end{array}$ & $\begin{array}{l}\text { Projeto } \\
\text { Pedagógico }\end{array}$ & Sim \\
\hline $\begin{array}{l}\text { Universidade Estadual do } \\
\text { Centro-Oeste (UNICENTRO) }\end{array}$ & $\begin{array}{l}\text { Guarapua } \\
\text { va }\end{array}$ & $\begin{array}{l}\text { Matriz } \\
\text { Curricular }\end{array}$ & Não \\
\hline $\begin{array}{l}\text { Universidade Estadual do } \\
\text { Paraná (UNESPAR) }\end{array}$ & $\begin{array}{l}\text { Campo } \\
\text { Mourão }\end{array}$ & $\begin{array}{l}\text { Matriz } \\
\text { Curricular }\end{array}$ & Não \\
\hline $\begin{array}{l}\text { Universidade Estadual do } \\
\text { Paraná (UNESPAR) }\end{array}$ & Paranavaí & $\begin{array}{l}\text { Matriz } \\
\text { Curricular }\end{array}$ & Não \\
\hline $\begin{array}{l}\text { Universidade Estadual do } \\
\text { Paraná (UNESPAR) }\end{array}$ & $\begin{array}{l}\text { União da } \\
\text { Vitória }\end{array}$ & $\begin{array}{l}\text { Matriz } \\
\text { Curricular }\end{array}$ & Sim \\
\hline $\begin{array}{l}\text { Universidade Estadual do } \\
\text { Paraná (UNESPAR) }\end{array}$ & $\begin{array}{l}\text { Paranagu } \\
\text { á }\end{array}$ & $\begin{array}{l}\text { Matriz } \\
\text { Curricular }\end{array}$ & Não \\
\hline $\begin{array}{l}\text { Universidade Estadual do } \\
\text { Norte Paraná (UENP) }\end{array}$ & $\begin{array}{l}\text { Cornélio } \\
\text { Procópio }\end{array}$ & $\begin{array}{c}\text { Projeto } \\
\text { Pedagógico e Matriz } \\
\text { Curricular }\end{array}$ & Não \\
\hline $\begin{array}{l}\text { Instituto Federal do Paraná } \\
\text { (IFPR) }\end{array}$ & Palmas & $\begin{array}{c}\text { Projeto } \\
\text { Pedagógico, Ementa } \\
\text { e Matriz Curricular }\end{array}$ & Sim \\
\hline $\begin{array}{l}\text { Universidade Tecnológica } \\
\text { Federal do Paraná (UTFPR) }\end{array}$ & $\begin{array}{l}\text { Pato } \\
\text { Branco }\end{array}$ & $\begin{array}{c}\text { Projeto } \\
\text { Pedagógico e Matriz } \\
\text { Curricular }\end{array}$ & Sim \\
\hline
\end{tabular}

Fonte: Os autores (2019)

Pelo estudo dos documentos que regem esses cursos notou-se que UNIOESTE (Cascavel e Foz do Iguaçu), UNICENTRO (Guarapuava), UNESPAR (Campo Mourão, Paranavaí e Paranaguá) e UENP (Cornélio Procópio) não abordam o uso ou ensino mediado por tecnologia, e que em oposição a elas, sete universidades trazem menções, de dois diferentes tipos sobre tecnologias, descritos a partir desse momento.

\section{A TECNOLOGIA ABORDADA EM DISCIPLINAS}


UEM (à distância e presencial), UNESPAR (União da Vitória), UTFPR (Pato Branco), IFPR (Palmas) e UEPG tem em seu currículo matérias que tratam de tecnologia.

A UEM oferta o curso de Letras Português/Inglês na modalidade não presencial e disponibiliza a disciplina Novas Tecnologias no Ensino de Língua Estrangeira - com 17 horas de aula prática e 17 horas de aula teórica, somando carga horária de 34 horas. Essa disciplina, ofertada no primeiro semestre do $5^{\circ}$ ano, tem como objetivo "o desenvolvimento e estudo de novas tecnologias no ensino de Língua Estrangeira como recurso de aprendizagem a partir de uma concepção de linguagem como forma de interação, articulada com a formação do profissional. (UEM, 2010, p. 17)". Além disso, pretende:

\begin{abstract}
criar oportunidades para que o aluno-professor desenvolva sua habilidade de compreensão e produção de linguagem escrita e oral dentro dos diversos gêneros textuais necessários para a utilização de novos recursos tecnológicos. - Estimular o desenvolvimento e a expressão de um posicionamento crítico em relação aos assuntos abordados. - Estimular o desenvolvimento de uso de novas tecnologias ligados ao ensino de Língua Inglesa articulados com a formação crítica do profissional (UEM, 2010, p. 17).
\end{abstract}

Nota-se que a UEM no seu curso oferecido à distância pretende oferecer aulas que abordem a temática da tecnologia, por acreditar que essa pode tornar ainda mais rico o ato de ensinar e aprender. Com essa disciplina a UEM à distância demonstra realmente acreditar no que menciona em seu Projeto Pedagógico, quando diz que

a prática profissional na formação do professor, que não prescinde da observação e da ação direta, pode ser enriquecida com os recursos de tecnologias da informação, incluídos o computador e o vídeo, narrativas orais e escritas de professores, produções de alunos, situações simuladoras de ensino e estudos de casos. (UEM, 2010, p. 9)

No que diz respeito ao curso presencial da UEM foram analisados dois documentos, o Projeto Pedagógico e a Matriz Curricular. No entanto, seu Projeto Pedagógico menciona as tecnologias apenas pela oferta da disciplina optativa Novas Tecnologias no Ensino de Língua Inglesa, que pretende desenvolver e estudar as novas tecnologias no ensino de Língua Estrangeira "como recurso de aprendizagem a partir de uma concepção de linguagem como forma de interação, articulada com a formação do profissional" (UEM, 2018, p. 15), criando: 


\begin{abstract}
oportunidades para que o aluno-professor desenvolva sua habilidade de compreensão e produção de linguagem escrita e oral dentro dos diversos gêneros textuais necessários para a utilização de novos recursos tecnológicos; estimular o desenvolvimento e a expressão de um posicionamento crítico em relação aos assuntos abordados; estimular o desenvolvimento de uso de novas tecnologias ligados ao ensino de Língua Inglesa articulados com a formação crítica do profissional (UEM, 2018, p. 15).
\end{abstract}

A universidade demonstra estar cônscia da importância que a tecnologia desenvolve na interação do professor com os alunos, e dos alunos entre si, e da possibilidade de adquirir e manter um posicionamento crítico deste aluno/professor como profissional e ser humano. E, por meio desta disciplina, a UEM (modalidade presencial) procura cumprir com o objetivo que propôs a seu curso, de "disseminar e fomentar um trabalho dinâmico e integrado com a língua e literaturas, de modo a renovar os processos de ensino-aprendizagem, atualmente vigentes”, buscando essa renovação pelo uso da tecnologia (UEM, 2018, p. 1).

A UNESPAR (União da Vitória) aponta em sua Matriz Curricular a oferta da disciplina Novas Tecnologias do Ensino-Aprendizado de Língua Inglesa para o quarto ano, com carga horária de 72 horas. Porém, não há uma descrição dos objetivos dessa disciplina e nem do que pretende contemplar em relação à tecnologia.

A UTFPR (Pato Branco) registra em seu Projeto Pedagógico a orientação de que seu desejo é que seus currículos permitam a formação para a atividade docente, focando, dentre outros pontos no "uso de tecnologias da informação e da comunicação e de metodologias, estratégias e materiais de apoio inovadores" (UTFPR, 2011, p. 57). Para que isso possa ser implementado, esse campus tem no seu curso de Letras Português/Inglês a disciplina Educação e Tecnologia, ofertada no $2^{\circ}$ período, e cujo objetivo é estudar as TDIC e os "papéis dos aprendizes e dos educadores em ambientes de aprendizagem baseados" nelas, verificar seu impacto "em diferentes contextos educacionais", além de analisar a educação à distância mediada por elas (UTFPR, 2011, p. 73).

Apura-se, dessa forma, que a UTFPR (Pato Branco) evidencia seu cuidado em que os alunos aprendam sobre tecnologia por ofertar em sua grade curricular uma disciplina que atenda a esses propósitos. 
O IFPR (Palmas) faz menção à tecnologia nos seus três documentos analisados com a oferta no sexto período da disciplina Seminário Interdisciplinar de Práticas de Ensino: Metodologias Ativas e Tecnologias Digitais de Informação e Comunicação, com objetivo de

articulação e síntese dos componentes curriculares do período, na perspectiva de um trabalho pedagógico interdisciplinar. Elaboração e coordenação de projetos de ensino, pesquisa, extensão e inovação. Práticas pedagógicas mediadas por tecnologias digitais de informação e comunicação: o aluno da/na era digital; metodologias ativas e a personalização do ensino; softwares e aplicativos educacionais; e Ambientes Virtuais de Aprendizagem (IFPR, 2017, p. 112).

Dessa forma, pode-se notar que este curso pretende disponibilizar aos professores em formação o conhecimento necessário para o uso da tecnologia em sala de aula, compreendendo o universo tecnológico em que seus alunos estão inseridos, aprendendo também sobre qual tecnologia poderiam utilizar em diferentes situações. Além desta disciplina, o IFPR (Palmas) também oferta, no sexto período, Literatura Brasileira, cuja ementa é:

contexto sociocultural e histórico da produção literária realizada no Brasil, da segunda metade do século XX à contemporaneidade. Estudo dos autores e das produções literárias da Literatura Contemporânea. Reescritura, hibridismo e as tecnologias da comunicação na produção e recepção do texto literário (IFPR, 2017, p. 103).

É perceptível na instituição o objetivo de confrontar o conteúdo visto em sala, neste caso a Literatura Brasileira, com a tecnologia, revelando por meio dessa matéria quais tecnologias possuem vínculo com o texto literário. Mas não são apenas essas as disciplinas ofertadas que mencionam tecnologias. O IFPR (Palmas) possui em sua grade de disciplinas a optativa Novas Tecnologias Aplicadas ao Ensino de Línguas, porém, sobre esta não é dada nenhuma informação adicional no Projeto Pedagógico do Curso (IFPR, 2017, p. 74).

A UEPG disponibiliza duas disciplinas que buscam abordar o tema da tecnologia: Hipermídia e Ensino de Língua, que objetiva mostrar as tecnologias digitais em sentido amplo, e a disciplina Estudos Temáticos de Educação e Ensino de Língua Inglesa e Tecnologias, que visa promover a "discussão de temas variados que considerem inter- 
relação entre educação, língua inglesa e suas tecnologias" (UEPG, 2018, p. 37), evidenciando, desta forma, a preocupação em contemplar a tecnologia no seu currículo, bem como em relacioná-la com a educação e a língua inglesa.

Assim, após a análise dos documentos das instituições, descobriu-se que quatro universidades paranaenses com curso de Letras Português/Inglês abrangem a tecnologia em alguma disciplina de sua grade curricular, e que essas disciplinas demonstram, em suma, estimular o desenvolvimento, o uso e o estudo de novas tecnologias ligadas ao ensino de Língua Inglesa, reconhecendo-as como recursos de aprendizagem e, por esse motivo, demonstram ter foco na prática profissional do professor pela possibilidade de essa ser enriquecida com o uso da tecnologia.

Será discorrido a partir de agora a outra forma com que os documentos dessas universidades abarcam a tecnologia, como um dos objetivos do curso.

\section{A TECNOLOGIA ABORDADA COMO OBJETIVO DO CURSO}

De forma mais geral do que uma disciplina que trate de tecnologia, a UTFPR (Pato Branco), o IFPR (Palmas), a UNIOESTE (Marechal Cândido Rondon) e a UEPG mencionam a tecnologia como um dos objetivos de seus cursos de Letras Português/Inglês.

A UTFPR (Pato Branco) menciona no Projeto Pedagógico que o profissional ali licenciado deve, dentre outras coisas "assimilar criticamente novas tecnologias, novos conceitos científicos, bem como promover inovações tecnológicas e visualizar aplicações para a área de Letras" (UTFPR, 2011, p. 24). Assim sendo, não apenas faz menção a tecnologia no documento que rege seu curso, mas também a inclui como uma obrigação aos que cursam Letras Português/Inglês, valorizando a tecnologia e reconhecendo seu potencial nessa área. Como auxílio a esse cumprimento, a universidade disponibiliza aos acadêmicos laboratórios "para a prática de atividades relacionadas ao âmbito dos estudos" das TDIC (UTFPR, 2011, p. 102).

O laboratório de línguas e os laboratórios de informática destinam-se às atividades práticas do curso, as quais envolvem a aplicação de ferramentas tecnológicas necessárias para a prática docente, seja mais especificamente nas disciplinas relacionadas ao conhecimento de informática, seja nas disciplinas relacionadas ao estudo e a prática das línguas portuguesa e 
inglesa. Todos os laboratórios listados atendem de forma excelente às necessidades das disciplinas em termos de espaço, equipamentos e serviços (UTFPR, 2011, p. 102).

O IFPR (Palmas) expressa que seu curso de licenciatura se propõe a habilitar docentes capazes de "fazer uso de novas tecnologias e a compreender sua formação profissional como processo contínuo, autônomo e permanente" (IFPR, 2017, p. 21). Acrescenta ainda que o egresso neste curso deve ser capaz de fazer uso de novas tecnologias e "utilizar os conhecimentos da tecnologia como ferramenta facilitadora e modernizadora de sua atividade profissional” (IFPR, 2017, p. 35), atestando que o profissional da área da educação precisa saber "utilizar a tecnologia disponível e, acima de tudo, ser um provocador, um problematizador, com vistas a desencadear o processo de construção de conhecimentos no contexto em que atua" (IFPR, 2017, p. 36), demonstrando que a tecnologia é essencial àquele que é responsável por ensinar, sendo facilitadora e construtora de conhecimentos.

A UNIOESTE (Marechal Cândido Rondon) compreende o papel auxiliador que as tecnologias podem fornecer ao licenciado em Letras e atribui a seu curso o dever de contemplar as tecnologias "na medida em que coadunem com a natureza de cada disciplina e venham contribuir para uma maior efetividade da formação geral dada ao licenciado em Letras" (UNIOESTE, 2016, p. 7), e ainda, o Projeto Pedagógico traz que o docente deve

\footnotetext{
se valer, na medida do possível, com as Tecnologias da Informação e Comunicação disponíveis. $\mathrm{O}$ atendimento a esta meta geral, que surge meio que à guisa de missão do Curso, deve, portanto, incidir sobre a formação do professor que sabe pesquisar e que, na sua atuação, valendo-se das tecnologias disponíveis, atenta para o seu conteúdo específico mas também para as relações étnico-raciais, para a biodiversidade, para a cultura afrobrasileira, para a diversidade de gêneros e para a cidadania e para o direito, dentre outros temas transversais (UNIOESTE, 2016, p. 7).
}

A UEPG traz luz à Lei de Diretrizes e Bases da Educação Nacional (LDB) em seu Projeto Pedagógico ao mencionar que

uma das finalidades da educação superior é incentivar o trabalho de pesquisa e investigação científica, visando o desenvolvimento da ciência e da tecnologia e da criação e difusão da cultura, e, desse modo, desenvolver o entendimento do homem e do meio em que vive (UEPG, 2018, p. 9). 
Somado a isso, enfatiza o que destacam as Diretrizes Curriculares Nacionais para o Curso de Letras, de que o profissional em Letras deve ser capaz de fazer uso de novas tecnologias (UEPG, 2018, p. 17). Ao fazer menção a essas normas a UEPG valida seu interesse de que se faça uso de tecnologias na educação por possuírem um potencial de enriquecer a experiência de ensino/aprendizado.

Volta-se agora a pergunta mote deste estudo, respondendo a forma com que as universidades públicas no estado do Paraná expõem a tecnologia em seus documentos. Notou-se que quatro destas tem a tecnologia como um dos objetivos de seus cursos, com interesse em preparar futuros professores para trabalharem com ela em sala de aula, utilizando-a em seu trabalho, para que essa colabore com o seu ensino. Essas quatro instituições entendem, portanto, que o profissional licenciado em Letras deve ser habilitado para ser capaz de fazer uso de tecnologias e utilizá-la como ferramenta facilitadora de sua atividade profissional, principalmente no atual contexto social, no qual crianças e jovens se interessam cada vez mais por tecnologia, e esta seria, então, uma forma de granjear sua atenção.

A pesquisa realizada por Mello (2018) com professores de Inglês atuantes em escolas da Rede Estadual da cidade de Foz do Iguaçu (PR), cidade no estado deste estudo, perguntando-lhes, dentre outros questionamentos, se sua formação ofereceu subsídios para que utilizassem a TDIC em sala de aula para fins pedagógicos mostra como os graduandos observam o conhecimento que lhes foi ou não transmitido na sua formação inicial. Os dados obtidos apontaram para: 1) professores que receberam um conhecimento prático-didático (com práticas no laboratório de Informática, discussão sobre o uso das TDIC e de algumas ferramentas para estudo); 2) conhecimento teórico básico ou superficial; e 3) professores que afirmaram não terem recebido "nenhum conhecimento sobre as TDIC ou não souberam responder se na graduação tiveram esse tipo de conhecimento" (MELLO, 2018, p. 68). A autora enfatiza que alguns entrevistados relataram 
especialistas, distante dos problemas práticos dos professores. O contato com o uso das TDIC na graduação foi bem superficial, focando mais em conversas e comentários com alguns professores formadores (MELLO, 2018, p. 71).

Mello (2018, p. 72) atribui essa lacuna ou "distanciamento entre a teoria e a prática pedagógica" como relacionada a uma "formação baseada na reprodução de conhecimento", reflexo da distância destes professores formadores ao "cotidiano do alunado", o que resulta em um trabalho baseado no ideal exposto nos livros, e não da realidade escolar, e isso pode ser resultado do que Martins (2015, p. 224) também constatou, de que os professores formadores "usam a tecnologia na preparação de suas aulas, mas não estão dando exemplo ou servindo de modelo para seus alunos, futuros professores de línguas, de como usar pedagogicamente a tecnologia”.

\section{CONSIDERAÇÕES FINAIS}

Vimos que $50 \%$ das universidades públicas paranaenses que ofertam curso de Letras Português/Inglês não incluem as tecnologias em seus documentos, sendo essas UNIOESTE (Cascavel e Foz do Iguaçu), UNICENTRO (Guarapuava), UNESPAR (Campo Mourão, Paranavaí e Paranaguá) e UENP (Cornélio Procópio), o que pode evidenciar que remetem isso à prática individualizada de seus docentes, ficando na decisão de cada um, de forma pessoal, trazer ou não as tecnologias para suas aulas e para a preparação de seus alunos, visto não existir uma diretriz geral que norteie a prática de seus docentes.

As outras instituições mencionaram as tecnologias em seus documentos de duas formas: ofertando disciplinas que debatam a tecnologia ou por mencioná-la como um dos objetivos do curso, sendo seis universidades em um dos critérios, e quatro no outro. As universidades que possuem disciplinas são UTFPR (Pato Branco), IFPR (Palmas), UEM (presencial e a distância), UEPG e UNESPAR (União da Vitória), e as que possuem a tecnologia como um dos objetivos do curso são UNIOESTE (Marechal Cândido Rondon), UTFPR (Pato Branco), IFPR (Palmas) e UEPG, sendo que, o IFPR (Palmas), a UTFPR (Pato Branco) e a UEPG manifestaram-se nas duas categorias, demonstrando maior interesse em apresentar a tecnologia aos seus alunos. 
Retomamos aqui o já mencionado fato de que a tecnologia não ser utilizada pelos professores de português e inglês em sua práxis, ou não providenciar aos alunos os benefícios que seriam possíveis, se dá, em parte, devido à aprendizagem incipiente recebida, ou inexistente, na formação inicial em Letras Português/Inglês, visto que metade das universidades analisadas não a abordam em seus documentos, o que é um número expressivo. Essa falta de formação gera uma deficiência de conhecimento significativa à atuação profissional, que precisa ser compensada em cursos de pósgraduação lato sensu ou outros de formação continuada, de menor carga horária, que abordem essa temática, para suprir necessidades sentidas em sala de aula de se trabalhar com tecnologia, haja vista que os próprios alunos, da geração millennials, pedem aulas que as insiram.

Em conclusão, este trabalho que discutiu a formação inicial de professores de Português/Inglês acerca do uso pedagógico de tecnologias, aponta uma lacuna existente nesses cursos de licenciatura nas universidades públicas no estado do Paraná, haja vista metade não aludir às tecnologias, e, portanto, não fornecer orientações quanto ao modo como ela deverá ser posteriormente trabalhada na escola, havendo uma deficiência em como esses profissionais são capacitados para o seu uso em sala de aula. Pode ser percebido mais claramente por este estudo, ainda que um recorte do cenário nacional, o lapso visível entre a formação dada aos professores, a necessidade dos alunos e o que é solicitado aos professores por meio dos regimentos, o que aponta para a necessidade de reformulação da matriz curricular dos cursos de Letras Português/Inglês nas universidades paranaenses, buscando incluir maior atenção às tecnologias e ao seu uso metodológico nas práticas pedagógicas.

Como contribuição, ficam também as reflexões feitas a partir da análise documental dos cursos à luz de documentos norteadores da educação nacional, que podem balizar não apenas a reformulação de cursos de educação inicial como também continuada na área de Letras. Esse estudo pode ser ampliado para uma análise de cenário nacional, envolvendo universidades públicas e privadas, em diferentes modalidades de ensino, para alavancar o efetivo e contextualizado uso de tecnologias na educação.

\section{BIBLIOGRAFIA}

Programas de Pós-Graduação em Ciências Sociais e Filosofia - UNIOESTE - Rua da 
BAPTISTA, J. B. Reflexões de professores de inglês em formação inicial sobre o uso de tecnologias. Revista Brasileira de Linguística Aplicada (Impresso), V. 14, p. 533 $552,2014$.

BRASIL. Base Nacional Comum Curricular na prática da gestão escolar e pedagógica. Organização Tereza Perez. São Paulo: Editora Moderna. 2018. Disponível em: <https:// implantacaosfb.files.wordpress.com/2018/08/bncc_gestacc83oescolar.pdf>. Acesso em: 23 de jun. 2019.

BRASIL. Ministério da Educação. Diretrizes Curriculares Nacionais para a Educação Infantil. Brasília, 2010. Disponível em: <http://ndi.ufsc.br/files/2012/02/Diretrizes-Curriculares-para-a-E-I.pdf>. Acesso em: 24 de jun. 2019.

GIBSON, L. A.; SODEMAN, W. A. Millennials and technology: addressing the communication gap in education and practice. Organization Development Journal, 2014.

Disponível

em:

<https://www.academia.edu/12884862/Millennials_and_Technology_

Addressing_the_Communication_Gap_in_Education_and_Practice $>$. Acesso em: $08 \mathrm{de}$ jul. 2019.

GONÇALVES, M. T. L.; NUNES, J. B. C. Tecnologias de informação e comunicação: limites na formação e prática dos professores. In: 29a Reunião Anual da ANPED. Caxambu - MG: ANPED, $2006 . \quad$ Disponível em: <http://www.tabuleirodigital.com.br/twiki/pub/GEC/

TrabalhoAno2006/tecnologias_de_informacao.pdf>. Acesso em: 22 de jun. 2019.

INSTITUTO FEDERAL DO PARANÁ - IFPR. Ementa do Curso de Licenciatura em Letras. Palmas, 2017. Disponível em: <http://palmas.ifpr.edu.br/graduacao/letrasportuguesingles/ementa-letras/>. Acesso em: 22 de jun. 2019.

INSTITUTO FEDERAL DO PARANÁ - IFPR. Matriz Curricular do Curso de Licenciatura em Letras. Palmas, 2017. Disponível em: <http://palmas.ifpr.edu.br/wpcontent/uploads/2018/08/matriz-curricular-letras-ingles.pdf $>$. Acesso em: 24 de jun. 2019.

INSTITUTO FEDERAL DO PARANÁ - IFPR. Projeto Pedagógico do Curso de Licenciatura em Letras. Palmas, 2017. Disponível em: $<$ http://palmas.ifpr.edu.br/graduacao/ letras-portuguesingles/ppc-letrasinglesportugues/>. Acesso em 21 de dez. 2018.

MARTINS, C. B. M. J. A integração da tecnologia nos cursos de licenciatura em letras do estado do Paraná a partir da perspectiva dos professores: um estudo de métodos mistos. 404 f. Tese de Doutorado. Programa de Pós-Graduação em Tecnologia, Universidade Tecnológica Federal do Paraná, Curitiba, Paraná, Brasil, 2015. 
MATEUS, E. F. Os professores na era digital e os (des)usos do computador na fase de formação inicial. The Especialist (PUCSP), São Paulo, SP, V. 25, N. 2, p. 199 220, 2004.

MELLO, E. C. F. O uso de tecnologias nas aulas de língua inglesa no Ensino Fundamental II em Foz do Iguaçu/PR. 2018. 158 f. Dissertação (Mestrado em Ensino) - Universidade Estadual do Oeste do Paraná, Foz do Iguaçu, 2018.

UNIVERSIDADE ESTADUAL DE MARINGÁ - UEM. Resolução no 022/2010CI/CCH, de 31 de março de 2010. Disponível em: <http://portal.nead.uem.br/site/img/_9NU_files/ docs/022_10.pdf>. Acesso em: 22 de jun. 2019.

UNIVERSIDADE ESTADUAL DE MARINGÁ - UEM. Grade Curricular de Letras. s/d. Disponível em: <http://www.dlm.uem.br/index.php?conteudo=grade>. Acesso em: 22 de jun. 2019.

UNIVERSIDADE ESTADUAL DE MARINGÁ - UEM. Projeto Pedagógico do Curso de Letras. s/d. Disponível em: <http://sites.uem.br/pen/deg/apoio-aoscolegiados-aco/documentos/cursos-1/cursos/letras-matutino-noturno >. Acesso em: 20 de dez. 2018.

UNIVERSIDADE ESTADUAL DE PONTA GROSSA - UEPG. Projeto Pedagógico do Curso de Licenciatura em Letras Português/Inglês e Respectivas Literaturas. 2018. Disponível em: <https://prograd.sites.uepg.br/wp-content/uploads/2018/04/PPCINGLES.pdf>. Acesso em: 22 de dez. 2018.

UNIVERSIDADE ESTADUAL DO CENTRO OESTE - UNICENTRO. Currículo Pleno de Letras. 2010. Disponível em: $<$ https://www3.unicentro.br/proen/cursos/matrizes-curriculares/\#15361860687418805eefe-673d>. Acesso em: 22 de jun. 2019.

UNIVERSIDADE ESTADUAL DO NORTE DO PARANÁ - UENP. Matriz Curricular da Graduação em Letras. 2013. Disponível em: <https://uenp.edu.br/letras-ingles-matriz>. Acesso em: 22 de jun. 2019.

UNIVERSIDADE ESTADUAL DO NORTE DO PARANÁ - UENP. Projeto Pedagógico da Graduação em Letras. 2018. Disponível em: <https://uenp.edu.br/letras-ingles>. Acesso em: 22 de jun. 2019.

UNIVERSIDADE ESTADUAL DO OESTE DO PARANÁ - UNIOESTE. Resolução n. 286/2016 - CEPE, de 8 de dezembro de 2016. Disponível em: <http://www.unioeste.br/ servicos/arqvirtual/arquivos/2862016-CEPE.pdf >. Acesso em: 24 de jun. 2019. 
UNIVERSIDADE ESTADUAL DO OESTE DO PARANÁ - UNIOESTE. Resolução $\mathrm{n}^{\mathbf{0}}$ 210/2016 - CEPE, de 6 de outubro de 2016. Disponível em: <http://www.unioeste.br/ servicos/arqvirtual/arquivos/2102016-CEPE.pdf >. Acesso em: 22 de dez. 2018.

UNIVERSIDADE ESTADUAL DO OESTE DO PARANÁ - UNIOESTE. Resolução $n^{0}$ 214/2015-CEPE, de 10 de dezembro de 2015. Disponível em: <http://www.unioeste.br/ servicos/arqvirtual/arquivos/2142015-cepe.pdf?15:43:46>. Acesso em: 23 de jun. 2019.

UNIVERSIDADE ESTADUAL DO PARANÁ - UNESPAR. Matriz Curricular do Curso de Letras. s/d. Disponível em: $\langle$ http://paranavai.unespar.edu.br/graduacao/graduacao/letras-1>. Acesso em: 22 de jun. 2019.

UNIVERSIDADE ESTADUAL DO PARANÁ - UNESPAR. Matriz Curricular Português/Inglês. 2010. Disponível em: <http://paranagua.unespar.edu.br/graduacao/ letras/estrutura-letras/matriz-curricular-portugues-ingles>. Acesso em: 23 de jun. 2019.

UNIVERSIDADE ESTADUAL DO PARANÁ - UNESPAR. Matriz de Letras. 2011. Disponível em: <http://prograd.unespar.edu.br/sobre/cursos/uniao-da-vitoria/cursoletras-port-e-ingles.pdf $>$. Acesso em: 22 de jun. 2019.

UNIVERSIDADE ESTADUAL DO PARANÁ - UNESPAR. Matriz Letras Português/Inglês. $2004 . \quad$ Disponível em: 〈http://prograd.unespar.edu.br/sobre/cursos/campo-mourao/letras-port-ingles.pdf $>$. Acesso em: 23 de jun. 2019.

UNIVERSIDADE TECNOLÓGICA FEDERAL DO PARANÁ - UTFPR. Disciplinas Letras Português/Inglês. s/d. Disponível em: <http://www.utfpr.edu.br/estruturauniversitaria/pro-reitorias/prograd/catalogo-de-cursos-da-utfpr/pato-branco/licenciaturaem-letras-portugues-ingles>. Acesso em: 24 de jun. 2019.

UNIVERSIDADE TECNOLÓGICA FEDERAL DO PARANÁ - UTFPR. Projeto Pedagógico do Curso de Licenciatura em Letras Português - Inglês da UTFPR, Campus Pato Branco. 2011. Disponível em: $<$ http://www.utfpr.edu.br/patobranco/estruturauniversitaria/diretorias/dirgrad/cursos/colet/disciplinas/disciplinas>. Acesso em: 03 de jan. 2019.

VERASZTO, E. V.; SILVA, D.; MIRANDA, N. A.; SIMON, F. O. Tecnologia: buscando uma definição para o conceito. Prisma.com, V. 1, p. 60 - 85, 2008. 